\title{
Patients suffer from shock: so does wine
}

\author{
Shaun R. McCann ${ }^{1}$
}

Received: 12 June 2019 / Accepted: 14 June 2019 / Published online: 22 July 2019

(c) Springer Nature Limited 2019

\author{
'Not bad for a kid from the sticks' \\ Jim Barrett (1926-2013). Owner of Chateau \\ Montelena, Napa Valley, CA
}

Shock is divided into four main types based on the underlying cause: low volume, cardiogenic, obstructive, and distributive shock. Low volume shock may be from bleeding, vomiting or pancreatitis. Cardiogenic shock may be due to a heart attack or cardiac contusion. Obstructive shock may be due to cardiac tamponade or a tension pneumothorax. Distributed shock may be due to sepsis, spinal cord injury or certain overdoses.

Septic shock is a potentially fatal condition that occurs when sepsis leads to dangerously low blood pressure and abnormalities in cellular metabolism. The Third International Consensus Definitions for Sepsis and Septic Shock (Sepsis-3) defines septic shock as a subset of sepsis in which particularly profound circulatory, cellular, and metabolic abnormalities are associated with a greater risk of mortality than with sepsis alone. Patients with septic shock can be clinically identified by a vasopressor requirement to maintain a mean arterial pressure of $65 \mathrm{~mm} \mathrm{Hg}$ or greater and serum lactate level $>2 \mathrm{mmol} / \mathrm{L}(>18 \mathrm{mg} / \mathrm{dL})$ in the absence of hypovolemia.

Bacterial infections are among the major complications of haematopoietic cell transplant (HCT) [1, 2]. From a transplanter's point of view we were always taught to fear Gram-negative sepsis in neutropenic patients. Fortunately, over the decades, numerous successful strategies have been developed to limit the negative impact of these infections. In fact, with the universal use of prompt empirical antibiotic

Shaun R. McCann

shaunrmccann@gmail.com

1 Haematology Emeritus, University of Dublin, Trinity College, Dublin, Ireland therapy in case of fever during neutropenia and, in some settings, antibiotic prophylaxis, the fatality rate dropped significantly [3]. The most frequent clinical entities following HCT are bloodstream infections (BSI), pneumonia and gastrointestinal infections, which include typhlitis and infections due to Clostridium difficile.

In my 30 years' experience of haemopoietic cell transplantation (HCT), Gram-positive sepsis has overtaken Gram-negative infection as a cause for concern. Although each transplant centre needs to know its own flora and fauna, infections with bacteria, such as Clostridium difficile (Gram positive), are a major problem.

Can shock occur in wines? Although still an area of controversy ...it probably does. "Bottle shock", also sometimes called "bottle sickness", happens to wine that has either been recently bottled or undergone a long journey-across an ocean or even a country. The term is used to describe a wine that seems disjointed when opened and poured; the wine doesn't taste as if the flavours are melding together in the way they should. It isn't corked [4] or oxidised, it just seems flat.

Bottle shock may be the result of wine being shaken as, for example, in a suitcase, through the mail or on an airplane. Continuous vibration can upset elements in wine causing it to 'shut down'. Frequent changes in temperature and variations of lighting may also play a role. Older wines with sediment may become murky when they are shaken during travel. The good news, however, is that time will cure most cases of 'bottle shock'.

The most famous use of the term 'bottle shock' was in the film of that name about Steven Spurrier's wine challenge in 1974, which resulted in Chateau Montelena winning, in a blind tasting, a competition for Californian white wines against French wines. The film was directed by Randall Miller and starred the late Alan Rickman as Steven Spurrier, and although there are many factual inaccuracies in the film [Jim and Bo never boxed each other, and Mike Grgich, the Croatian-American wine maker, and Patricia Gallagher (Spurrier's colleague) are not mentioned] my wife and I enjoyed it. It was released in 2008 and prompted 


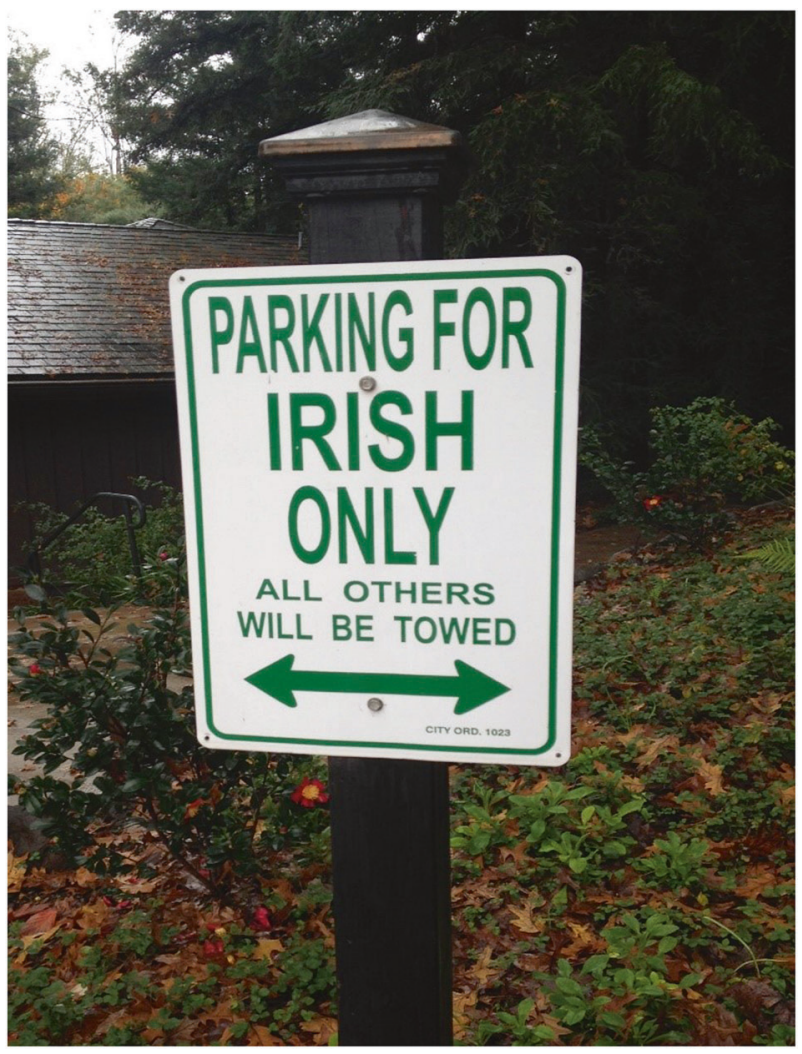

Fig. 1 Parking sign in Chateau Montelena

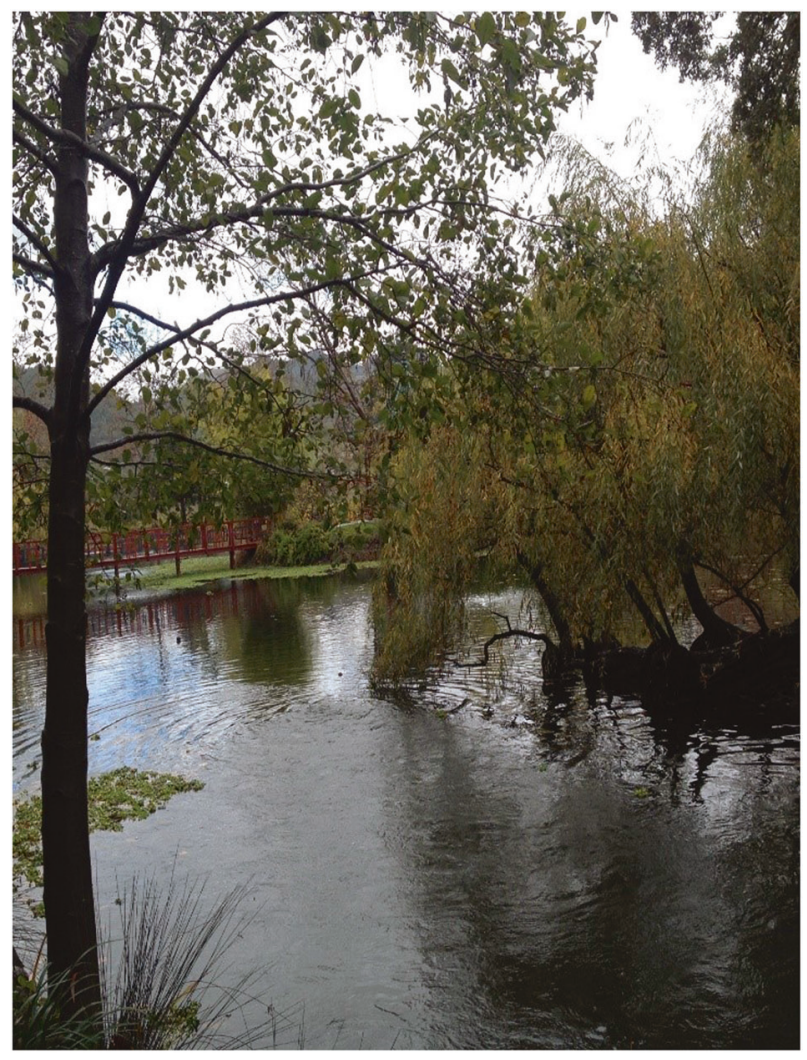

Fig. 2 Chinese gardens in Chateau Montelena a visit by us to Chateau Montelena in 2014. We were a little taken aback when we saw a sign in the car park (Fig. 1), but then of course remembered that Jim Barrett, the owner, was from Wexford in Ireland. We met Bo, his son, who now runs the vineyard. He was very pleasant even though he was significantly more follicularly challenged than Bo in the film! After a tasting we explored the beautiful grounds of the vineyard.

In 1882, Alfred L. Tubbs purchased 254 acres of land near Calistoga in Napa Valley. The venture, although successful at first, came to an end with prohibition. In 1958, Yort and Jeanie Frank from Hong Kong bought the chateau and developed the beautiful Chinese gardens (Fig. 2). In the early 1970s Jim Barrett bought and replanted the vineyard, and as they say 'the rest is history'.

Certainly, the wines we tasted did not suffer from 'bottle shock'.

\section{Compliance with ethical standards}

Conflict of interest The author declares that he has no conflict of interest.

Publisher's note: Springer Nature remains neutral with regard to jurisdictional claims in published maps and institutional affiliations.

\section{References}

1. Miller HK, Braun TM, Stillwell T, Harris AC, Choi S, Conneally J, et al. Infectious risk following allogeneic hematopoietic cell transplant complicated by acute graft-versus-host disease. Biol Blood Marrow Transplant. 2017;23:522-8.

2. García-Cadenas I, Rivera I, Martino R, Esquirol A, Barba P, Novelli $\mathrm{S}$, et al. Patterns of infection and infection-related mortality in patients with steroid-refractory acute graft versus host disease. Bone Marrow Transplant. 2017;52:107-13.

3. Schouster MG, Cleveland AA, Dubberke ER, Kauffman CA, Avery RK, Hussain $S$, et al. Infections in hematopoietic cell transplant recipients: results from the organ transplant project, a multicenter, prospective, cohort study. Open Forum Infect Dis. 2017;4:ofx50. https://doi.org/10.1093/ofid/ofx50

4. Wine Spectator. Dr Vinny's Archive; 2019. 